\section{Coexistent aortic dissection and hepatocellular carcinoma with elevated plasma transforming growth factor $\beta$ level: Possible roles of fibrillin 1 and transforming growth factor $\beta$}

Hisato Takagi, MD, PhD, Hideaki Manabe, MD, Seishiro Sekino, MD, Takayoshi Kato, MD, Yukihiro Matsuno, MD, PhD, and Takuya Umemoto, MD, PhD, Shizuoka, Japan

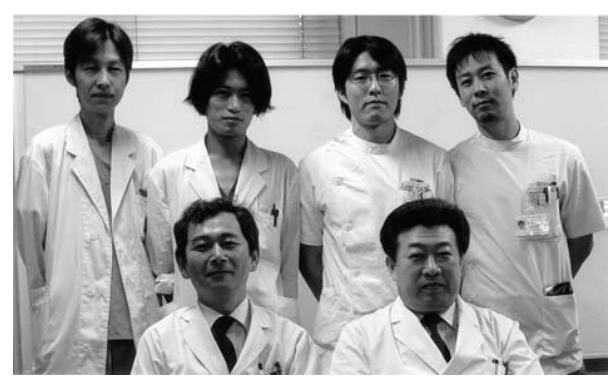

Front row, left to right: Drs Umemoto and Takagi; back row, left to right: Drs Matsuno, Kato, Sekino, and Manabe

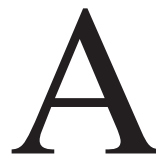

mutation in the fibrillin 1 gene, $F B N 1$, is responsible for reduced fibrillin deposition into the extracellular matrix and produces a mild form of autosomal dominantly inherited weakness of elastic tissue, which predisposes toward ascending aortic aneurysm and dissection later in life. ${ }^{1}$ Activation of transforming growth factor $\beta$ (TGF- $\beta$ ) has been demonstrated in the lungs of fibrillin 1 -deficient mice, ${ }^{2}$ and loss of fibrillin 1 microfibrils leads to multiple phenotypic features that may result in part from activation of TGF- $\beta .{ }^{3}$ On the other hand, TGF- $\beta$, a particularly well-studied cytokine widely regarded as profibrogenic in liver injury, represents a potentially important link between fibrosis and neoplasia in the liver. ${ }^{4}$ We describe here coexistent aortic dissection and hepatocellular carcinoma (HCC) in a patient with elevated plasma TGF- $\beta$ level. We also discuss some possible roles of fibrillin 1 and TGF- $\beta$ in these two disorders.

\section{Clinical Summary}

An 88-year-old man with chest pain was referred to our department. He showed no traits of Marfan syndrome on physical examination. Computed tomographic scanning disclosed both Stanford type A acute aortic dissection (Figure 1, $A$ ) and hepatic tumor, relatively hypodense in the delayed phase (Figure 1, $B$ ). Urgent replacement of the ascending aorta with retrograde cerebral perfusion and deep hypothermic circulatory arrest of the lower half of the body was successfully performed, and the pathologic examination of the aortic wall revealed cystic medial necrosis. Testing for hepatitis B virus surface antigen was negative, but testing for hepatitis $\mathrm{C}$ virus antibody was positive. Serum alpha fetoprotein, serum protein induced by vitamin $\mathrm{K}$ antagonist II, and plasma TGF- $\beta_{1}$ levels were increased to 16.5

\footnotetext{
From the Department of Cardiovascular Surgery, Sizuoka Medical Center, Shizuoka, Japan.

Received for publication June 18, 2004; accepted for publication June 28, 2004.

Address for reprints: Hisato Takagi, MD, PhD, Department of Cardiovascular Surgery, Sizuoka Medical Center, 762-1 Nagasawa, Shimizu-cho, Sunto-gun, Shizuoka 411-8611, Japan (E-mail: kfgth973@ybb.ne.jp).

J Thorac Cardiovasc Surg 2005;129:462-3

$0022-5223 / \$ 30.00$

Copyright (C) 2005 by The American Association for Thoracic Surgery doi:10.1016/j.jtcvs.2004.06.033
}

$\mathrm{ng} / \mathrm{mL}$ (reference $<10.0 \mathrm{ng} / \mathrm{mL}$ ), $2740 \mathrm{mAU} / \mathrm{mL}$ (reference $<40 \mathrm{mAU} / \mathrm{mL}$ ), and $7.47 \mathrm{ng} / \mathrm{mL}$ (reference $1.56-3.24 \mathrm{ng} / \mathrm{mL}$ ), respectively. Postoperative computed tomographic scanning disclosed that the hepatic lesion was hyperdense in the arterial phase (Figure 1,C). The hepatic tumor was clinically diagnosed as HCC, and transcatheter arterial embolization is scheduled for after recovery from the aortic surgery.

\section{Discussion}

Franke and associates' pulse-chase studies ${ }^{1}$ revealed normal fibrillin synthesis but reduced fibrillin deposition into the extracellular matrix in cultured fibroblasts from 10 individuals of a kindred, none of whom had classic Marfan syndrome, in which ascending aortic disease, ranging from mild aortic root enlargement to aneurysm or dissection, was identified. Neptune and collaborators ${ }^{2}$ noted markedly greater immunoreactivity of TGF- $\beta$ in lung sections from mice deficient in fibrillin 1 than in wild-type littermates. Isogai and colleagues ${ }^{3}$ have proposed that interactions between latent TGF- $\beta$-binding protein 1 and fibrillin 1 may stabilize latent TGF- $\beta$ complexes in the extracellular matrix, and it is possible that loss of fibrillin 1 would abolish this stabilization and lead to activation of TGF- $\beta$. In a study from Abou-Shady and coworkers, ${ }^{5}$ TGF- $\beta$ demonstrated a marked messenger RNA overexpression in HCC relative to normal controls, whereas the levels of TGF- $\beta$ receptors showed no significant changes. Intense TGF- $\beta$ immunostaining was found in HCC cells and in the perineoplastic stroma with immunohistochemical techniques, whereas no or mild immunostaining was present in the normal liver. The upregulation of TGF- $\beta$ in HCC suggests an important role for these isoforms in hepatic carcinogenesis and tumor progression. Ours is the first report of coexistent aortic dissection and HCC in the literature to our knowledge and suggests some roles of fibrillin 1 and TGF- $\beta$ in these two disorders. Reduced fibrillin 1 deposition into the extracellular matrix may cause aortic dissection and lead to activation of TGF- $\beta$, and this activated TGF- $\beta$ might affect the initiation or progression of HCC.

\section{References}

1. Francke U, Berg MA, Tynan K, Brenn T, Liu W, Aoyama T, et al. A Gly1127Ser mutation in an EGF-like domain of the fibrillin-1 gene is a risk factor for ascending aortic aneurysm and dissection. Am J Hum Genet. 1995;56:1287-96. 

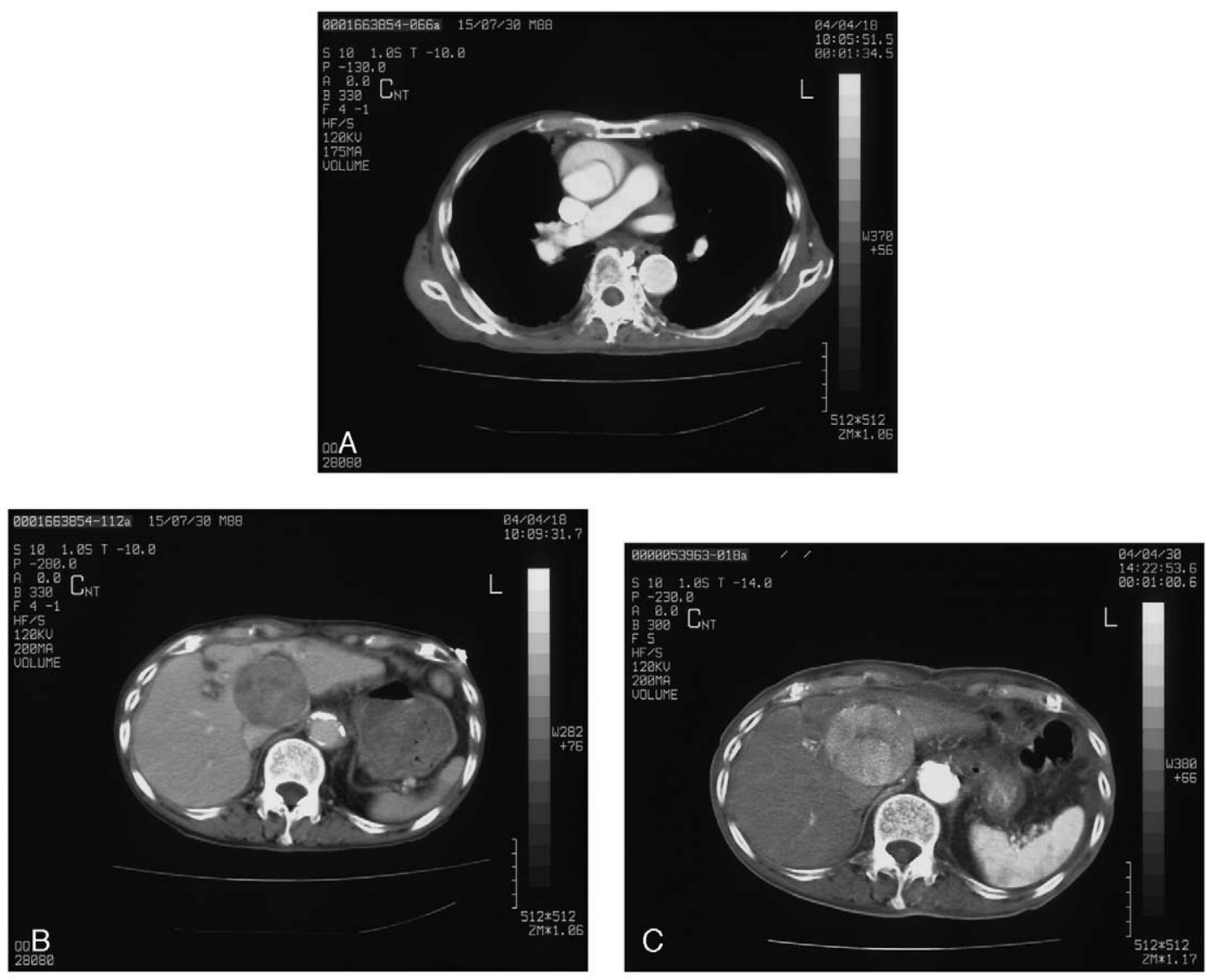

Figure 1. Computed tomographic scanning disclosed both Stanford type $A$ acute aortic dissection (A) and hepatic tumor, relatively hypodense in delayed phase (B). Postoperative computed tomographic scanning revealed hepatic lesion to be hyperdense in arterial phase (C).

2. Neptune ER, Frischmeyer PA, Arking DE, Myers L, Bunton TE, Gayraud B, et al. Dysregulation of TGF- $\beta$ activation contributes to pathogenesis in Marfan syndrome. Nat Genet. 2003;33:407-11.

3. Isogai Z, Ono RN, Ushiro S, Keene DR, Chen Y, Mazzieri R, et al. Latent transforming growth factor $\beta$-binding protein 1 interacts with fibrillin and is a microfibril-associated protein. J Biol Chem. 2003;278:2750-7.
4. Bissell DM. Chronic liver injury, TGF-beta, and cancer. Exp Mol Med. 2001;33:179-90.

5. Abou-Shady M, Baer HU, Friess H, Berberat P, Zimmermann A, Graber $\mathrm{H}$, et al. Transforming growth factor betas and their signaling receptors in human hepatocellular carcinoma. Am J Surg. 1999;177: 209-15. 